Vol. 4, No. 2, Nopember 2018

p-ISSN: 2442-8884 / e-ISSN: 2541-4542

J-Kesmas

Jurnal Kesehatan Masyarakat

\title{
EFEKTIVITAS SENAM HAMIL DAN YOGA HAMIL TERHADAP PENURUNAN NYERI PUNGGUNG PADA IBU HAMIL TRIMESTER III DI PUSKESMAS PEKKABATA
}

\author{
Lina Fitriani
}

Stikes Bina Generasi Polewali Mandar

Email: Lina_adhy_cinta@yahoo.co.id

\begin{abstract}
ABSTRAK
Nyeri punggung bawah pada ibu hamil trimester III terjadi karena perubahan hormonal yang menimbulkan perubahan pada jaringan lunak penyangga dan penghubung sehingga menurunnya elastisitas dan fleksibilitas otot. Prevalensi nyeri punggung bawah pada kehamilan dilaporkan bervariasi dari 50\% di Inggris dan Skandinavia serta 70\% di Australia. Berdasarkan laporan Profil Data Kesehatan Indonesia tahun 2015 terdapat 5.298.285 orang ibu hamil di Indonesia, di wilayah Provinsi Jawa Tengah jumlahnya ada 314.492 orang, di wilayah kota Semarang 53.734 orang ibu hamil mengalami nyeri punggung bawah. Dari 50 ibu hamil trimester III yang ada di Puskesmas Pekkabata, ada 30 orang ibu hamil yang mengalami nyeri punggung. Tujuan penelitian ini adalah untuk mengetahui efektivitas senam hamil dan yoga hamil dalam menurunkan keluhan nyeri punggung bawah pada ibu hamil trimester III serta untuk mengetahui perbandingan efektivitas dari keduanya. Metode penelitian ini menggunakan metode penelitian Quasi eksperimen dengan rancangan penelitian two grup pre test - post test yang berupaya untuk menganalisis efektivitas senam hamil dan yoga hamil terhadap penurunan nyeri punggung bawah. Populasi dalam penelitian ini adalah semua ibu hamil trimester III di wilayah kerja Puskesmas Pekkabata pada bulan Januari - Desember. Penilaian dilakukan dengan cara mengkaji tingkat nyeri punggung bawah ibu hamil sebelum dan sesudah dilakukan senam hamil atau yoga hamil. Banyaknya sampel dalam penelitian ini adalah 20 responden.
\end{abstract}

Kata Kunci: Senam Hamil, Yoga Hamil, Nyeri Punggung Bawah

PENDAHULUAN

Masa kehamilan dimulai dari konsepsi sampai lahirnya janin. Lamanya hamil normal adalah 280 hari (40 minggu atau 9 bulan 7 hari) dihitung dari hari pertama haid terakhir. Kehamilan dibagi dalam 3, triwulan pertama dimulai dari hasil konsepsi sampai 3 bulan, triwulan kedua dimulai dari bulan keempat sampai 6 bulan, triwulan ketiga dari bulan ketujuh sampai 9 bulan (Saifuddin, 2008).
Berdasarkan Kementerian

Kesehatan Republik Indonesia

(Kemenkes RI) tahun 2016, jumlah ibu hamil di Indonesia mencapai 5.354.594 orang. Sedangkan jumlah ibu hamil di Provinsi Sulawesi Barat

tahun 2016 sebesar 35.437 orang (Kemenkes RI, 2016). Jumlah ibu hamil di Puskesmas Pekkabata Kabupaten Polewali Mandar tahun 2017 sebanyak 830 orang ibu hamil dan jumlah persalinan di Puskesmas Pekkabata tahun 2017 sebanyak 716 orang (Dinkes 
Polewali Mandar, 2017), sedangkan jumlah ibu hamil trimester III yang tercatat di Puskesmas Pekkabata 3 bulan terakhir yaitu pada bulan Oktober 64 orang, bulan November 78 orang dan bulan Desember 66 orang ibu hamil.

Ketidaknyamanan yang biasa terjadi pada ibu hamil trimester III yaitu konstipasi atau sembelit, edema atau pembengkakan, insomnia, nyeri punggung bawah (nyeri pinggang), kegerahan, sering buang air kecil, hemorhoid, heart burn (panas dalam perut), perut kembung, sakit kepala, susah bernafas, varices (Mochtar Rustam 2009).

Berdasarkan kajian yang dilakukan oleh Bullock et. Al (1987) menemukan bahwa sekitar $88,2 \%$ wanita hamil yang mengalami nyeri punggung. Pada usia kehamilan 14 - 22 minggu, sekitar 62\% wanita hamil yang melaporkan kejadian nyeri punggung bawah (Brayshaw, 2008). Sedangkan penelitian yang dilakukan oleh Amy (2009), sekitar $70 \%$ dari ibu hamil mengalami sakit pinggang low back pain (LBP) yang mungkin dimulai sejak awal trimester, puncak kejadian LBP terjadi pada trimester II dan III kehamilan.

Nyeri punggung bawah (Nyeri pinggang) merupakan nyeri punggung yang terjadi pada area lumbosakral. Nyeri punggung bawah biasanya akan meningkat intensitasnya seiring pertambahan usia kehamilan karena nyeri ini merupakan akibat pergeseran pusat gravitasi wanita tersebut dan postur tubuhnya. Perubahan-perubahan ini disebabkan oleh berat uterus yang membesar.Nyeri punggung juga bisa disebabkan karena membungkuk yang berlebihan, berjalan tanpa istirahat, angkat beban.Hal ini diperparah apabila dilakukan dalam kondisi wanita hamil sedang lelah.Mekanika tubuh yang tepat saat mengangkat beban sangat penting diterapkan untuk menghindari peregangan otot tipe ini (Mochtar Rustam 2009).

Keluhan nyeri pinggang yang dialami oleh ibu hamil tentunya tidak bisa dibiarkan begitu saja. Menurut $\mathrm{Yu}$ (2010) salah satu cara untuk meningkatkan kesehatan selama kehamilan adalah dengan melakukan olahraga ringan seperti senam hamil. Senam hamil adalah suatu bentuk latihan guna memperkuat dan mempertahankan elastisitas otot-otot dinding perut, ligamen-ligamen, serta otot dasar panggul yang berhubungan dengan proses persalinan. Latihan ini berfungsi untuk memperkuat stabilitas inti tubuh yang akan membantu memelihara kesehatan tulang belakang. Mempunyai kekuatan tubuh yang baik dapat meningkatkan risiko trauma tulang belakang ataupun jatuh pada saat hamil.

Secara ringkas petunjuk senam hamil berupa konsultasi/pemeriksaan kesehatan, dilakukan mulai umur kehamilan 28 minggu, membutuhkan ruangan yang nyaman dan pakaian yang sesuai, minum yang cukup baik sebelum, selama dan setelah melakukan senam, melakukan senam 3x seminggu/teratur, melakukan pemanasan dan pendinginan, tidak menahan nafas selama latian, hentikan bila timbul keluhan, bila dilakukan di rumah sakit senam hamil dipandu dan 
Vol. 4, No. 2, Nopember 2018

p-ISSN: 2442-8884 / e-ISSN: 2541-4542

J-Kesmas

Jurnal Kesehatan Masyarakat

terdapat sosialisasi (Anik \& Yetty 2011:52).

Menurut penelitian yang dilakukan oleh Puspitasari (2013) tentang hubungan senam hamil dengan nyeri pinggang pada ibu hamil di RS Kendangsari Surabaya dengan hasil $P$ value $=0,000$ yang artinya Ho ditolak artinya ada hubungan yang bermakna antara ibu hamil yang melakukan senam hamil dengan nyeri pinggang. Semakin teratur mengikuti senam hamil maka hal ini dapat meminimalkan nyeri pinggang yang dirasakan oleh ibu hamil.

Yoga hamil merupakan bentuk pengobatan fisik dan spiritual yang sudah digunakan 5000 tahun yang lalu.Teknik yang digunakan pada saat yoga membawa keseimbangan pada aspek tubuh, pikiran dan kepribadian yang berbeda sehingga penggunaannya penuh dengan energi, kekuatan dan kejelasan tujuan hidup (Keegan, 2001 cit Handayani, 2010).

Prenatal yoga (yoga selama hamil) adalah salah satu jenis modifikasi dan hatha yoga yang disesuaikan dengan kondisi ibu hamil. Tujuan prenatal yoga adalah mempersiapkan ibu hamil secara fisik, mental dan spiritual untuk proses persalinan (Tia Pratignyo 2014).

Yoga dalam kehamilan menggabungkan postur-postur khusus dan teknik-teknik yang bermanfaat bagi ibu hamil dan membantu menghilangkan ketidaknyamanan yang disebabkan oleh perubahan tubuh selama kehamilan.Yoga adalah sebuah ilmu yang menjelaskan kaitan antara fisik, mental, dan spiritual manusia untuk mencapai kesehatan yang menyeluruh (Sindhu, 2009).

Pada ibu hamil di daerah Polewali Mandar, yoga hamil masih jarang dilakukan dari pada senam hamil.Selama ini ibu hamil menganggap bahwa keluhan nyeri punggung merupakan hal yang wajar terjadi selama kehamilan sehingga upaya yang selama ini mereka lakukan untuk mengurangi keluhan nyeri punggung bawah yaitu dengan melakukan istirahat.

Berdasarkan uraian di atas maka peneliti merasa tertarik untuk melakukan penelitian tentang "Efektivitas senam hamil dan yoga hamil terhadap penurunan nyeri punggung pada ibu hamil trimester III di Puskesmas Pekkabata Polewali Mandar tahun 2018.

\section{METODE PENELITIAN}

Jenis dan Metode Penelitian

Penelitian ini menggunakan metode penelitian quasieksperiment dengan rancangan penelitian two group pretest dan posttest design.Pada penelitian ini menganalisis perbedaan senam hamil dan yoga hamil terhadap penurunan nyeri punggung bawah pada ibu hamil trimester III.

\section{Lokasi dan Waktu Penelitian}

Penelitian ini telah dilaksanakan pada bulan Januari - Desember 2018 di wilayah kerja Puskesmas Pekkabata Polewali Mandar.

HASIL DAN PEMBAHASAN

\section{Hasil Penelitian}

\section{Analisis Univariat}

Tabel 1.

Distribusi Responden Berdasarkan Umur

\begin{tabular}{lll}
\hline Umur & Frekuensi & Persentase \\
\hline
\end{tabular}


Vol. 4, No. 2, Nopember 2018

J-Kesmas

Jurnal Kesehatan Masyarakat

\begin{tabular}{ccc}
\hline $15-19$ & 1 & 5 \\
$20-24$ & 3 & 15 \\
$25-29$ & 4 & 20 \\
$30-34$ & 8 & 40 \\
$35-39$ & 4 & 20 \\
\hline Total & 20 & $100 \%$ \\
\hline
\end{tabular}

Sumber : data primer 2018

Berdasarkan tabel 1 hasil

penelitian menunjukkan bahwa dari 20 orang responden usia antara 15-19 tahun sebanyak 1 orang (5\%), usia 20 24 tahun sebanyak 3 orang (15\%), usia 25-29 tahun sebanyak 4 orang (20\%), usia 30-34 tahun sebanyak 8 orang (40\%), dan usia 35-39 tahun sebanyak 4 orang $(10 \%)$.

Tabel 2.

Distribusi Responden Berdasarkan Tingkat Pendidikan

\begin{tabular}{lll}
\hline Pendidikan & Frekuensi & Persentase \\
\hline TDS & 0 & 0 \\
SD & 7 & 35 \\
SMP & 5 & 25 \\
SMA & 7 & 35 \\
PT & 1 & 5 \\
\hline Total & 20 & $100 \%$
\end{tabular}

Sumber : data primer 2018

Berdasarkan tabel 2 hasil penelitian menunjukkan bahwa dari 20 Orang responden, terdapat 7 orang (35\%) tingkat pendidikan SD, 5orang (25\%) tingkat pendidikan SMP, 7 orang (35\%) tingkat pendidikan SMA dan 1 orang (5\%) tingkat pendidikan PT.

Tabel 3.

Distribusi Responden Berdasarkan Umur Kehamilan

\begin{tabular}{lll}
\hline Umur Kehamilan & Frekuensi & Persentase \\
\hline $28-30$ & 6 & 30
\end{tabular}

p-ISSN: 2442-8884 / e-ISSN: 2541-4542

\begin{tabular}{lll}
$31-37$ & 14 & 70 \\
\hline Total & 20 & $100 \%$
\end{tabular}

Sumber : data primer 2018 Berdasarkan tabel 3 hasil penelitian menunjukkan bahwa dari 20 Orang responden, terdapat 6 orang (30\%) usia kehamilan antara 28-30 minggu, dan 14 orang (70\%) usia kehamilan 31-37 minggu.

Tabel 4.

Distribusi Responden Berdasarkan Tingkat Nyeri Pre Test Senam Hamil

\begin{tabular}{ccc}
\hline Skala Nyeri & Frekuensi & Persentase \\
\hline 1 & 3 & 30 \\
2 & 1 & 10 \\
4 & 3 & 30 \\
5 & 3 & 30 \\
\hline Total & 10 & 100 \\
\hline
\end{tabular}

Sumber : data primer 2018

Berdasarkan tabel 4 hasil penelitian menunjukkan bahwa untuk skala nyeri pre-test senam hamil terdapat 3 orang dengan skala nyeri 1, 1 orang dengan skala nyeri 2, 3 orang dengan skala nyeri 4 dan 3 orang dengan skala nyeri 5 .

Tabel 5.

Distribusi Responden Berdasarkan Tingkat Nyeri Post Test Senam Hamil

\begin{tabular}{ccc}
\hline $\begin{array}{c}\text { Skala } \\
\text { Nyeri }\end{array}$ & Frekuensi & Persentasi \\
\hline 0 & 6 & 60 \\
1 & 2 & 20 \\
2 & 2 & 20 \\
\hline
\end{tabular}


Vol. 4, No. 2, Nopember 2018

J-Kesmas

Jurnal Kesehatan Masyarakat

\begin{tabular}{lll}
\hline Total & 10 & 100
\end{tabular}

Sumber : data primer 2018

Berdasarkan tabel 5 hasil

penelitian menunjukkan bahwa untuk skala nyeri post-test senam hamil terdapat 6 orang dengan skala nyeri 0,2 orang dengan skala nyeri 1 dan 2 orang dengan skala nyeri 2 .

Tabel 6.

Distribusi Responden berdasarkan tingkat nyeri pre test yoga hamil

\begin{tabular}{lll}
\hline Skala Nyeri & Frekuensi & Persentasi \\
\hline 1 & 1 & 10 \\
3 & 3 & 30 \\
4 & 2 & 20 \\
5 & 2 & 20 \\
6 & 2 & 20 \\
\hline Total & 10 & 100
\end{tabular}

Sumber : data primer 2018

Berdasarkan tabel 6 hasil penelitian menunjukkan bahwa untuk skala nyeri pre-test yoga hamil terdapat 1 orang dengan skala nyeri 1, 3 orang dengan skala nyeri 3, 2 orang dengan skala nyeri 4, 2 orang dengan skala nyeri 5 dan 2 orang dengan skala nyeri 6.

Tabel 7.

Distribusi Responden Berdasarkan Tingkat Nyeri Post Test Yoga Hamil

Sumber: data primer 2018

Berdasarkan tabel 7 hasil penelitian menunjukkan bahwa untuk skala nyeri post-test yoga hamil terdapat 4 orang dengan skala nyeri 0,2 orang dengan skala nyeri 1, 3 orang dengan
p-ISSN: 2442-8884 / e-ISSN: 2541-4542

skala nyeri 2 dan 1 orang dengan skala nyeri 3 .

\section{Analisis Bivariat}

Tabel 8

Perbandingan efektivitas senam hamil dan yoga hamil terhadap keluhan nyeri punggung bawah pada ibu hamil trimester III

\begin{tabular}{cccccccc}
\hline & \multicolumn{2}{c}{ SENAM } & & \multicolumn{3}{c}{ YOGA } \\
\hline $\begin{array}{c}\text { Pre- } \\
\text { test }\end{array}$ & $\begin{array}{c}\text { Post- } \\
\text { test }\end{array}$ & $\begin{array}{c}\text { Pre- } \\
\text { Post }\end{array}$ & P.value & $\begin{array}{c}\text { Pre- } \\
\text { test }\end{array}$ & $\begin{array}{c}\text { Post- } \\
\text { test }\end{array}$ & $\begin{array}{c}\text { Pre- } \\
\text { Post }\end{array}$ & P.value \\
\hline 1 & 0 & 1 & & 1 & 0 & 1 & \\
1 & 0 & 1 & 0.000 & 3 & 0 & 3 & 0.000 \\
1 & 0 & 1 & & 3 & 1 & 2 & \\
2 & 0 & 2 & 3 & 2 & 1 & \\
4 & 0 & 4 & 4 & 1 & 3 & \\
4 & 1 & 3 & 4 & 0 & 4 & \\
4 & 1 & 3 & 5 & 0 & 5 & \\
5 & 0 & 5 & 5 & 2 & 3 & \\
5 & 2 & 3 & 6 & 2 & 4 & \\
5 & 2 & 3 & 6 & 3 & 3 & \\
& & 26 & & Mean & 29
\end{tabular}

Sumber : data primer 2018

Berdasarkan tabel 8 hasil penelitian menunjukkan dimana terdapat penurunan skala nyeri sebelum dan sesudah senam hamil dengan total nilai rata-rata penurunan yaitu 26 dan nilai p.value 0,000 yang artinya $\mathrm{Ho}$ ditolak berarti ada hubungan yang bermakna antara ibu hamil yang melakukan senam hamil dengan penurunan nyeri punggung. Begitupun

\begin{tabular}{ccc}
\hline Skala Nyeri & Frekuensi & Persentasi \\
\hline 0 & 4 & 40 \\
1 & 2 & 20 \\
2 & 3 & 30 \\
3 & 1 & 10 \\
\hline Total & 10 & 100 \\
\hline
\end{tabular}


Vol. 4, No. 2, Nopember 2018

J-Kesmas

Jurnal Kesehatan Masyarakat

juga dengan yoga hamil terdapat penurunan skala nyeri sebelum dan sesudah yoga hamil dengan total nilai rata-rata penurunan yaitu 29 dan nilai p.value 0,000 yang artinya Ho ditolak artinya ada hubungan yang bermakna antara ibu hamil yang melakukan yoga hamil dengan penurunan nyeri punggung.

\section{PEMBAHASAN}

Peneliti telah melakukan penelitian di wilayah kerja Puskesmas Pekkabata Polewali Mandar untuk mengetahui efektivitas senam hamil dan yoga hamil terhadap penurunan nyeri punggung bawah pada ibu hamil trimester III. Masing - masing kelompok senam hamil dan yoga hamil ini terdiri dari 10 ibu hamil jadi total responden adalah 20 orang ibu hamil yang mengalami nyeri punggung bawah. Menggunakan teknik Purposive Sampling.Selanjutnya peneliti akan membahas hubungan antara variable independen dengan variable dependen yang diteliti oleh peneliti.

\section{Senam Hamil terhadap Penurunan Nyeri Punggung pada Ibu Hamil Trimester III}

Sebelum melakukan uji T-Test data berpasangan, terlebih dahulu dilakukan uji normalitas dan didapatkan data berdistribusi normal.

Berdasarkan hasil penelitian menggunakan uji t-test terdapat penurunan skala nyeri sebelum dan sesudah senam hamil dengan total nilai rata-rata penurunan yaitu 26 dan nilai p.value 0,000 yang artinya Ho ditolak berarti ada hubungan yang bermakna

antara ibu hamil yang melakukan senam hamil dengan penurunan nyeri punggung.

Berdasarkan hasil penelitian di atas dapat disimpulkan bahwa senam hamil dapat memberikan keuntungan untuk mempertahankan dan meningkatkan kesehatan fisik ibu hamil, memperlancar peredaran darah, mengurangi keluhan kram atau pegalpegal, dan mempersiapkan pernafasan, aktivitas otot dan panggul untuk menghadapi proses persalinan (Anik dan Yetty 2011).

\section{Yoga Hamil terhadap Penurunan Nyeri Punggung pada Ibu Hamil Trimester III}

Berdasarkan hasil penelitian menggunakan uji t-test dapat disimpulkan bahwa terdapat penurunan skala nyeri sebelum dan sesudah dilakukan yoga hamil dengan total nilai rata-rata penurunan yaitu 29 dan nilai p.value 0,000 yang artinya Ho ditolak artinya ada hubungan yang bermakna antara ibu hamil yang melakukan yoga hamil dengan penurunan nyeri punggung.

Berdasarkan hasil penelitian di atas dapat disimpulkan bahwa yoga hamil dapat membawa keseimbangan pada aspek tubuh, pikiran dan kepribadian yang berbeda sehingga penggunanya penuh dengan energi, kekuatan dan kejelasan tujuan hidup.Ketika seorang wanita hamil melakukan secara rutin (2-3 kali) setiap minggu selama kehamilan, dapat menjaga elastisitas dan kekuatan ligament panggul, pinggul dan otot kaki sehingga mengurangi rasa nyeri yang 
Vol. 4, No. 2, Nopember 2018

J-Kesmas

Jurnal Kesehatan Masyarakat

timbul saat persalinan serta memberikan ruang untuk jalan lahir (Rusmita Eli).

\section{Efektivitas Senam Hamil dan Yoga Hamil terhadap Penurunan Nyeri Punggung pada Ibu Hamil Trimester III}

Dari hasil penelitian dapat disimpulkan bahwa diantara 2 kelompok perlakuan yaitu senam hamil dan yoga hamil yang lebih efektif dalam menurunkan nyeri punggung pada ibu hamil adalah yoga hamil. Dapat dilihat dari nilai mean yoga hamil yang lebih besar dari pada nilai mean senam hamil.

Hal ini sejalan dengan teori yang dikemukakan oleh Tia Pratignyo (2014) bahwa yoga hamil dapat mengurangi keluhan fisik secara umum semasa kehamilan, seperti nyeri punggung, nyeri panggul, hingga pembengkakan bagian tubuh.

Hal ini juga sejalan dengan penelitian yang dilakukan oleh (Field et al2014) yang menyatakan bahwa yoga memiliki efek lebih positif untuk ibu hamil dalam mengurangi stress, kecemasan dan gangguan tidur pada ibu hamil.

Sejalan dengan penelitian yang dilakukan oleh (Rao et al, 2015) sebuah tinjauan sistematis yoga efektif untuk mengurangi kecemasan, depresi dan rasa sakit akut maupun kronis pada populasi dewasa tanpa efek samping.Intervensi yoga meningkatkan kesehatan psikologis (kecemasan, depresi, tertekan, stress) dan dapat meningkatkan kualitas hidup.

Menurut pengamatan peneliti berdasarkan teori dan penelitian terkait, yoga dapat menurunkan nyeri punggung

pada ibu hamil dengan menggunakan teknik relaksasi yang dapat dilakukan dengan cara membayangkan sesuatu yang menyenangkan sehingga dapat membuat tubuh menjadi rileks, dapat menjaga elastisitas dan kekuatan ligament panggul, pinggul dan otot kaki.

\section{KESIMPULAN DAN SARAN \\ Kesimpulan}

Setelah dilakukan penelitian tentang efektivitas senam hamil dan yoga hamil terhadap keluhan nyeri punggung bawah pada ibu hamil trimester III di Puskesmas Pekkabata, Kec. Polewali, Kab.Polewali Mandar, maka dapat ditarik kesimpulan bahwa:

1.Senam hamil efektif dalam menurunkan nyeri punggung bawah pada ibu hamil trimester III dilihat dari hasil pre-test hingga post test yang mengalami penurunan dengan hasil pvalue $=0,000$ dan nilai mean yaitu 26 .

2. Yoga hamil efektif dalam menurunkan nyeri punggung bawah pada ibu hamil trimester III dilihat dari hasil pre-test hinggapost test yang mengalami penurunan dengan hasil $\mathrm{p}$ value $=0,000$ dan nilai mean yaitu 29 .

3.Terdapat perbedaan efektivitas yang bermakna antara senam hamil dan yoga hamil terhadap keluhan nyeri punggung bawah pada ibu hamil trimester III dilihat dari nilai rata-rata senam hamil yaitu 26 dan nilai rata-rata yoga hamil yaitu 29. Dengan demikian, yoga hamil lebih efektif dalam menurunkan nyeri punggung bawah.

\section{Saran}

1.Bagi Institusi Pendidikan 
Vol. 4, No. 2, Nopember 2018

J-Kesmas

Jurnal Kesehatan Masyarakat

Diharapkan intitusi pendidikan dapat menjadikan penelitian ini sebagai bahan referensi penelitian selanjutnya, memperbanyak referensi di perpustakaan yang menyangkut tentang senam hamil, yoga hamil dan nyeri punggung bawah pada ibu hamil trimester III.

\section{Bagi Puskesmas Pekkabata}

Diharapkan Puskesmas Pekkabata dapat menambahkan kegiatan senam hamil dan yoga hamil dalam program kerja Puskesmas Pekkabata.

3. Bagi Profesi Bidan

Sebaiknya tenaga kesehatan dalam hal ini bidan dapat meningkatkan mutu pelayanan kesehatan khususnya dalam mengurangi keluhan nyeri punggung bawah ibu hamil trimester III dengan mengajarkan dan membantu ibu hamil menerapkan senam hamil atau yoga hamil di rumah.

\section{DAFTAR PUSTAKA}

Agnesti, Renvilia dan Hendrik Linggarjati. 2009. Senam Hamil Praktis. Yogyakarta: Media Pressindo

Inding, Ilmiati. 2016. Pengaruh

Senam Hamil terhadap Perubahan Derajat Nyeri Pada Ibu Hamil yang Menderita Nyeri Pinggang Bawah (NPB).Skripsi.Fakultas Kedokteran Universitas Hasanuddin Makassar.

Latifin, Khoirul dan Satria Yudha Kusuma. 2014. Panduan Dasar Klinik Keperawatan. Malang: Penerbit Gunung Samudera.

Lockhart, Anita dan Lyndon Saputra.
p-ISSN: 2442-8884 / e-ISSN: 2541-4542

2014. Asuhan Kebidanan Kehamilan Fisiologis \& Patologis. Tangerang Selatan: Binarupa Aksara.

Manuaba, Ida Ayu Chandranita, dkk. 2010. Ilmu Kebidanan, Penyakit Kandungan dan KB. Jakarta: EGC.

Maryam, Siti. 2016. Perbedaan Senam Hamil dan Yoga Hamil Terhadap Kecemasan Menghadapi Persalinan. Tesis: Universitas Sebelas Maret Surakarta.

Megasari. 2015. Hubungan Senam Hamil Terhadap Nyeri Punggung pada Ibu Hamil Trimester III di RB Fatmawati. KTI: STIKes Hang Tuah Pekanbaru.

Mufdlilah. 2009. Panduan Asuhan Kebidanan Ibu Hamil. Jogjakarta: Nuha Medika.

Pratignyo, Tia. 2014. Yoga Ibu Hamil plus Postnatal Yoga. Jakarta: Pustaka Bunda.

Prawirohardjo, Sarwono. 2014. Ilmu Kebidanan. Jakarta: PT Bina Pustaka Sarwono Prawirohardjo.

Sindhu, Pujiastuti. Yoga untuk Kehamilan: Sehat, Bahagia dan Penuh Makna. Bandung: Mizan Digital Publishing.

Sofian, Amru. 2011. Rustam Mochtar Sinopsis Obstetri: Obstetri Operatif, Obstetri Sosial. Jakarta: EGC.

Suryati, Siti. 2014. Hubungan Senam Hamil dengan Nyeri Punggung pada Ibu Hamil di Puskesmas 
Vol. 4, No. 2, Nopember 2018

J-Kesmas

Jurnal Kesehatan Masyarakat

Pakisjaya Karawang. KTI:

Fakultas Kedokteran Universitas

Sebelas Maret Surakarta.

Sutarjo, Untung Suseno. Profil
p-ISSN: 2442-8884 / e-ISSN: 2541-4542

Kesehatan Indonesia Tahun 2016. Jakarta: Kementerian Kesehatan Republik Indonesia

Yusuf, A. Muri. 2017. Metode

Penelitian. Jakarta: Kencana 